\author{
Брянцева Т.А., канд. экон. наук, ст. преп., \\ Шевченко М.В., ст. преп. \\ Белгородский государственный технологический университет им. В.Г. Шухова
}

\title{
ОСОБЕННОСТИ ПРИМЕНЕНИЯ ОНЛАЙН-КАСС
}

\begin{abstract}
tatyana.shapoval@mail.ru
В статье рассматриваются особенности организации системы расчетов с применением онлайн-касс, устанавливаемые в связи с изменением федерального законодательства в 2017 году и призванные упростить осуществление налогового контроля за применением контрольно-кассовой техники организациями торговли, в том числе в сфере строительства.

Ключевые слова: кассовые операции, контрольно-кассовая техника, онлайн-касса, оператор фискальныхх данныхх, фискальный накопитель

В связи с принятием Федерального закона от 03 июля 2016 № 290-Ф3 «О внесении изменений в Федеральный закон «О применении контрольно-кассовой техники при осуществлении наличных денежных расчетов и (или) расчетов с использованием платежных карт» и отдельные законодательные акты Российской Федерации» значительно изменяется порядок осуществления торговых операций с применением контрольно-кассовой техники. Указанный документ предусматривает постепенный переход на онлайн-кассы, что позволит в оперативном режиме осуществлять передачу информации о наличных расчетах продавца в налоговую службу.

Принцип работы онлайн-касс заключается в том, что данные по пробитым чекам через операторов фискальных данных, с которыми у продавца заключен договор на обслуживание, будут передаваться на сервер налоговой

службы, зарегистрировавшей кассовый аппарат. С технической точки зрения это будет выглядеть следующим образом: в начале рабочего дня кассир составляет отчет о начале смены, в конце рабочего дня - отчет о закрытии. Через 24 часа после начала смены возможность сформировать чек заканчивается. В момент осуществления кассовой операции, когда продавец пробивает чек, онлайн-касса формирует фискальный признак и отправляет его на проверку оператору. Оператор проверяет данную информацию и в случае ее достоверности в течение примерно 1,5 секунд высылает компании уникальный код - подтверждение. Касса сохранит чек с этим кодом и фискальным признаком. Оформить продажу без уникального номера невозможно. Оператор фискальных данных передает информацию о пробитых чеках в налоговую службу в режиме онлайн. Принцип работы онлайн-кассы представлен на рис.1.
\end{abstract}

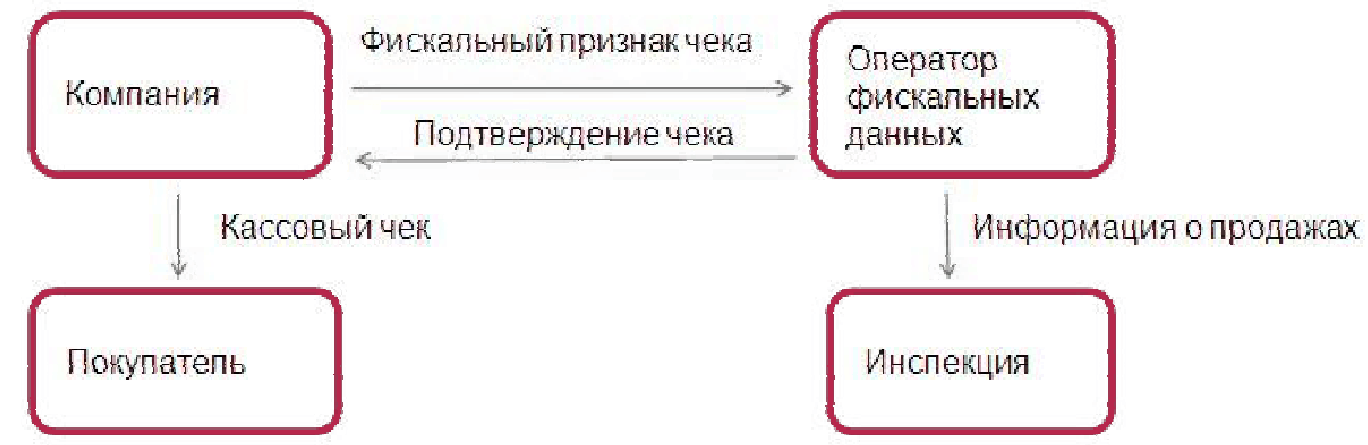

Рис. 1. Принцип работы онлайн-кассы [11]

Кроме того, согласно новому порядку, продавец обязан будет переслать электронный чек покупателю на электронную почту, если покупатель предоставит такие данные. Также, сохраняется действие и бумажных чеков, которые дополнят QR кодом для проверки покупателем факта передачи сведений о совершенной покупке в налоговую службу.

$\mathrm{B}$ связи с этим, кассовый чек будет дополнен новыми реквизитами, к которым, в частности, относятся:

- информация о системе налогообложения;

- данные о месте, в котором совершена операция (адрес офлайн магазина или адрес сайта, если это интернет-магазин);

- разновидность расчета (приход или расход);

- форма расчета (наличными или 
электронными средствами);

- номер, присвоенный оператором фискальных данных;

- номер регистрации, присвоенный в ККТ;

- номер кассового накопителя, присвоенный на заводе;

- наименование оператора фискальных данных;

- адрес оператора фискальных данных в сети интернет;

- адрес электронной почты или номер телефона покупателя.

Переход на онлайн-кассы планируется осуществлять в пять этапов:

1 этап: с 15 июля 2016 года по 30 июня 2017 года. В этот период использование онлайнкассы носит добровольный характер. Также на данном этапе возможна модернизация имеющейся кассы и еe перерегистрация в налоговой инспекции;

2 этап: с 1 февраля 2017 года по 1 июля 2017 года. На данном этапе предполагается переход на обязательное использование онлайнкасс. Налоговые инспекции перестанут регистрировать кассы, не отвечающие новым требованиям. Однако в этот период разрешено еще использование ККТ, зарегистрированных до 1 февраля 2017 года;

3 этап: с 1 июля 2017 года. Данный этап характеризуется обязательным применением онлайн-касс всеми организациями и индивидуальными предпринимателями. Исключение составят организации и предприниматели на ЕНВД; индивидуальные предприниматели на патентной системе налогообложения; организации и индивидуальные предприниматели, оказывающие услуги населению;

4 этап: с 1 января 2018 года.Формирование и выдача кассовых чеков будет осуществляться только в электронном виде. Бумажные чеки будут выдаваться покупателям только по их просьбе;

5 этап: с 1 июля 2018 года. Установление обязанности применения онлайн-касс организациями и индивидуальными предпринимателями, находящимися на ЕНВД; индивидуальными предпринимателями на патентной системе налогообложения; организациями и индивидуальными предпринимателями, оказывающими услуги населению; организациями и индивидуальными предпринимателями, использующими торговые автоматы.

Кроме того, необходимо отметить, что в соответствии с законодательством РФ от применения онлайн-ККТ освобождены следующие хозяйствующие субъекты: организации, занимающиеся мелкими бытовыми услугами (ремонтом обуви, уходом за детьми и т.д.), продажей некоторых видов товаров (обуви и одежды из кожи, компьютерной техники, музыкальных инструментов, велосипедов, газет, мороженого, талонов и билетов), а также компании, находящиеся в труднодоступных местностях, где нет Интернета.

В табл.1 представлены особенности применения онлайн-ККТ в зависимости от вида осуществляемой деятельности.

Каждый хозяйствующий субъект, попадающий под действие Ф3 № 290-Ф3 от 03.07.2016 года, вправе выбрать для себя наиболее удобный способ перехода на онлайнККТ. Первый способ предусматривает модернизацию уже имеющегося кассового аппарата: установку фискального накопителя и специального программного обеспечения. Однако необходимо отметить, что доработке подлежат только некоторые модели.

При невозможности реализации первого варианта, организация вынуждена будет приобрести новый кассовый аппарат, технические возможности которого отвечают требованиям законодательства. В соответствии с Ф3 54-Ф3 от 22.05.2003 года (ред. от 03.07.2016) контрольно-кассовая техника должна отвечать следующим требованиям [4]:

- иметь корпус;

- иметь заводской номер, нанесенный на корпус;

- иметь внутри корпуса часы реального времени, а также устройство для печати фискальных документов;

- осуществлять проверку контрольного числа регистрационного номера контрольнокассовой техники, обеспечивающего проверку корректности ввода пользователем регистрационного номера в контрольнокассовую технику;

- обеспечивать в момент расчета прием информации о сумме расчета от устройства;

- обеспечивать возможность установки фискального накопителя внутри корпуса и при применении контрольно-кассовой техники содержать фискальный накопитель внутри корпуса;

- передавать фискальные данные в фискальный накопитель, установленный внутри корпуса;

- обеспечивать формирование фискальных документов в электронной форме;

- исключать возможность формирования (печати) кассового чека (бланка строгой отчетности), кассового чека коррекции (бланка 
строгой отчетности коррекции), содержащих сведения более чем об одном признаке расчета;

- обеспечивать возможность передачи фискальных документов, сформированных с использованием любого фискального накопителя, включенного в реестр фискальных накопителей, любому оператору фискальных данных сразу после записи фискальных данных в фискальный накопитель;

- обеспечивать печать фискальных документов, за исключением случая осуществления расчетов с использованием электронных средств платежа в сети «Интернет»;

- обеспечивать возможность печати на кассовом чеке (бланке строгой отчетности) двухмерного штрихового кода (QR-код размером не менее $20 \times 20 \mathrm{mм}$ );

- принимать от технических средств оператора фискальных данных подтверждение оператора, в том числе в зашифрованном виде; - информировать пользователя об отсутствии подтверждения оператора переданного фискального документа в налоговые органы в электронной форме через оператора фискальных данных, а также о неисправностях в работе контрольно-кассовой техники;

- обеспечивать для проверяющего лица налогового органа возможность печати фискального документа «отчет о текущем состоянии расчетов» в любое время;

- обеспечивать возможность поиска по номеру любого фискального документа, записанного в фискальный накопитель, установленный внутри корпуса контрольнокассовой техники, а также его печать на бумажном носителе;

- исполнять протоколы информационного обмена и др.

Таблииа 1

Особенности применения онлайн-ККТ в зависимости от вида осуществляемой деятельности

\begin{tabular}{|c|c|}
\hline Бланки строгой отчетности & $\begin{array}{l}\text { С } 1 \text { июля } 2018 \text { года продавцы бланков строгой отчетности должны } \\
\text { будут отправлять сведения о выданных БСО в электронном виде в } \\
\text { налоговую инспекцию }\end{array}$ \\
\hline Продажи по банковским картам & $\begin{array}{l}\text { Принимая оплату банковской картой, продавец обязан сформиро- } \\
\text { вать кассовый чек }\end{array}$ \\
\hline Интернет-торговля & $\begin{array}{l}\text { Кассовый аппарат должен применяться независимо от формы рас- } \\
\text { четов } \\
\text { При доставке товара на дом, курьер должен иметь при себе кассо- } \\
\text { вый аппарат и выбивать чек в момент продажи товара }\end{array}$ \\
\hline Оказание услуг населению & Применение онлайн-касс обязательно с 1 июля 2018 года \\
\hline Комиссионная торговля & $\begin{array}{l}\text { Применение онлайн-КТТ обязательно за исключением случаев, ко- } \\
\text { гда в соответствии с законодательством ККТ можно не применять }\end{array}$ \\
\hline Продавцы на ЕНВД & $\begin{array}{l}\text { С } 1 \text { июля } 2018 \text { года обязанность применения онлайн-касс распро- } \\
\text { страняется и на экономических субъектов, применяющих ЕНВД. } \\
\text { Исключение составляют организации на ЕНВД, торгующие газета- } \\
\text { ми и журналами в розницу, при условии, что доля газет и журналов } \\
\text { в продажах составляет больше } 50 \text { процентов товарооборота и ассор- } \\
\text { тимент сопутствующих товаров утвержден органом исполнитель- } \\
\text { ной власти субъекта РФ; }\end{array}$ \\
\hline Организации на ЕСХН & $\begin{array}{l}\text { Обязанность применения онлайн-ККТ возникает с } 1 \text { февраля } 2017 \\
\text { года при приеме платежей за продукцию и услуги в наличной фор- } \\
\text { ме, за исключением продажи сельхозпродукции населению на роз- } \\
\text { ничных рынках, ярмарках и выставках }\end{array}$ \\
\hline Совмещение режимов & $\begin{array}{l}\text { При совмещении режимов применение онлайн-ККТ обязательно с } \\
1 \text { февраля } 2017 \text { года }\end{array}$ \\
\hline
\end{tabular}

Перечень контрольно-кассовой техники, отвечающей новым требованиям, включен в реестр ККТ, который ведет налоговая служба. Он представляет собой совокупность сведений о каждом изготовленном экземпляре модели контрольно-кассовой техники и представлен на сайте налоговой инспекции (www.nalog.ru.).

С принятием нового закона значительно упрощается порядок регистрации онлайн-ККТ в налоговой инспекции. Для этого теперь необходимо подать заявление в любую налоговую инспекцию либо в бумажном варианте, либо в электронной форме. В заявлении указывается следующая информация [4]:

- полное наименование организации (ФИО индивидуального предпринимателя);

- ИНН;

- адрес установки и применения ККТ; 
- наименование модели онлайн-кассы;

- заводской номер онлайн-ККТ;

- наименование модели фискального накопителя;

- заводской номер экземпляра модели фискального накопителя;

- номер автоматического устройства для расчетов (если ККТ применяется в составе автоматического устройства для расчетов);

- сведения о применении регистрируемой кассы в режиме, когда не требуется обязательная передача фискальных документов в налоговые органы в электронной форме;

- сведения о применении ККТ только при оказании услуг;

- сведения о применении ККТ только при расчетах в сети Интернет (если онлайн-касса используется только для таких расчетов);

- сведения о применении ККТ банковским платежным агентом, субагентом при приеме ставок и выплате выигрыша при организации и проведении азартных игр (в случае когда касса используется только для таких расчетов) и др.

Не позднее следующего рабочего дня налоговая инспекция должна сообщить регистрационный номер ККТ, который сразу заносится в фискальный накопитель. После чего в течение следующего дня необходимо сформировать отчет о регистрации и передать его в налоговую инспекцию в бумажном варианте, через кабинет ККТ либо через оператора фискальных данных. На основании данного отчета налоговая инспекция авторизирует пользователя онлайн-ККТ и используемый фискальный накопитель, проверит достоверность предоставленных данных.

Далее на основании данных из заявления налоговая служба формирует карточку регистрации ККТ и вносит необходимые сведения в журнал учета. Электронный вариант карточки направляется организации, зарегистрировавшей онлайн-кассу. При необходимости организация может получить бумажный вариант карточки регистрации ККТ при обращении в налоговую инспекцию.

Необходимо отметить важную особенность нового порядка регистрации онлайн-кассы: электронный документ должен быть подписан усиленной квалифицированной электронной подписью.

Кроме того, регистрации в налоговых органах подлежат также и фискальные накопители, применяемые для шифрования и хранения передаваемой в ФНС информации. На сегодняшний день в реестр фискальных накопителей включена модель фискального накопителя

(криптографическое)

«Шифровальное

фискальных данных фискальный накопитель «ФН-1», срок использования которого составляет 13 месяцев.

В табл.2 представлена сравнительная характеристика старых моделей ККТ и онлайнкасс.

Также необходимо отметить, что с принятием федерального закона от 03 июля 2016 № 290-ФЗ устанавливается новая система штрафов за несоблюдение вводимых требований (Табл.3), размер которых зависит от суммы оплаты, на которую не оформили чек.

Подводя итог вышесказанному, можно сделать вывод о том, что введение онлайн-касс, прежде всего, направлено на упрощение действующего порядка осуществления налогового контроля за применением контрольно-кассовой техники. Однако, на наш взгляд, данная мера будет иметь как положительные, так и отрицательные последствия. К преимуществам использования онлайн-касс можно отнести:

- ужесточение контроля за торговой деятельностью хозяйствующих субъектов, осуществляемого в режиме реального времени, при одновременном упрощении процесса его реализации и минимизации количества выездных проверок;

- получение дополнительного источника бюджетных доходов;

- повышение уровня защиты покупателей;

- упорядочение и контроль торговой деятельности интернет-магазинов;

- упрощение порядка регистрации и перерегистрации онлайн-ККТ, снятия ее с учета;

- возможность быстрого получения хозяйствующим субъектом подробной информации об основных показателях работы бизнеса;

- организации, использующие онлайн-кассы вправе отказаться от форм первичной учетной документации (КМ-1, КМ-2, КМ-3, КМ-4, КМ-5, КМ-6, КМ-7, КМ-8, КМ-9);

- доступность электронного чека для покупателя в любой момент.

Однако, несмотря на все преимущества, введение онлайн-касс повлечет за собой и определенные неудобства, к числу которых относятся:

- дополнительные расходы на модернизацию и приобретение кассового аппарата, отвечающего новым требованиям;

- дополнительные расходы на услуги интернет-провайдера;

- дополнительные расходы на услуги оператора фискальных данных;

- технические сложности при обеспечении доступа к интернету в отдаленных районах. 
Сравнительная характеристика старых моделей ККТ и онлайн-касс

\begin{tabular}{|c|c|c|}
\hline Признак сравнения & Старая модель & Онлайн-касса \\
\hline Порядок регистрации кассы & $\begin{array}{c}\text { Регистрация осуществляется } \\
\text { только при личном присутствии в } \\
\text { ФНС }\end{array}$ & $\begin{array}{c}\text { Регистрация осуществляется либо при } \\
\text { личном присутствии в ФНС, либо } \\
\text { путем подачи заявления в электрон- } \\
\text { ном виде через Интернет на сайте } \\
\text { ФНС }\end{array}$ \\
\hline $\begin{array}{c}\text { Необходимость заключения } \\
\text { договора с Центром } \\
\text { технического } \\
\text { обслуживания } \\
\end{array}$ & Обязательно & Можно не заключать договор \\
\hline Наличие голограммы & $\begin{array}{c}\text { Обязательна. За отсутствие - } \\
\text { штраф до } 10000 \text { руб. }\end{array}$ & Не нужна \\
\hline Подключение к Интернету & Не нужно & $\begin{array}{c}\text { Обязательно. При отсутствии связи, } \\
\text { неполадки должны быть устранены в } \\
\text { течение } 30 \text { календарных дней, иначе } \\
\text { касса заблокируется }\end{array}$ \\
\hline Расходы на посредника & Отсутствуют & $\begin{array}{c}\text { Передача информации о чеках в ФНС } \\
\text { осуществляется через оператора фис- } \\
\text { кальных данных, оплата услуг кото- } \\
\text { рого вызывает дополнительные рас- } \\
\text { ходы у организации }\end{array}$ \\
\hline $\begin{array}{c}\text { Порядок выдачи кассового } \\
\text { чека }\end{array}$ & $\begin{array}{c}\text { Покупателю выдается бумажный } \\
\text { чек, содержащий } 7 \text { обязательных } \\
\text { реквизитов }\end{array}$ & $\begin{array}{c}\text { Покупателю предоставляется чек в } \\
\text { электронном виде, который содержит } \\
24 \text { обязательных реквизита. По требо- } \\
\text { ванию покупателя может быть выдан } \\
\text { бумажный экземпляр }\end{array}$ \\
\hline Информация о выручке & $\begin{array}{c}\text { Информация записывается } \\
\text { на ЭКЛЗ, а она попадает } \\
\text { в инспекцию при проверках }\end{array}$ & $\begin{array}{c}\text { Информация из чеков записывается } \\
\text { на фискальный накопитель } \\
\text { и в режиме онлайн передается в ФНС }\end{array}$ \\
\hline
\end{tabular}

\section{Система штрафов за нарушение порядка применения онлайн-касс}

\begin{tabular}{|c|c|c|}
\hline \multirow{2}{*}{ Вид нарушения } & \multicolumn{2}{|c|}{ Вид наказания } \\
\cline { 2 - 3 } & для должностных лиц & $\begin{array}{c}\text { для организаций и индивидуальных } \\
\text { предпринимателей }\end{array}$ \\
\hline Компания не применяла кассу & $\begin{array}{c}\text { от 25 \% до 50 \% суммы расчета вне } \\
\text { кассы (минимум 10 тыс. руб.) }\end{array}$ & $\begin{array}{c}\text { от 75 \% до 100 \% суммы расчета вне } \\
\text { кассы (минимум 30 тыс. руб.) }\end{array}$ \\
\hline $\begin{array}{c}\text { Компания не применяла кассу } \\
\text { (повторное нарушение), и сум- } \\
\text { ма расчетов превысила 1 млн } \\
\text { руб. }\end{array}$ & $\begin{array}{c}\text { дисквалификация на срок до одно- } \\
\text { го года }\end{array}$ & $\begin{array}{c}\text { приостановка деятельности на срок } \\
\text { до 90 суток }\end{array}$ \\
\hline $\begin{array}{c}\text { Применение кассы, не соответ- } \\
\text { ствующей требованиям, нару- } \\
\text { шение правил регистрации }\end{array}$ & предупреждение или штраф \\
$\begin{array}{c}\text { ККТ, сроков и условий ее пере- } \\
\text { регистрации, порядка ее при- } \\
\text { менения }\end{array}$ & на 1,5-3 тыс. руб. & предупреждение или штраф \\
на 5-10 тыс. руб.
\end{tabular}

\section{БИБЛИОГРАФИЧЕСКИЙ СПИСОК}

1. Кодекс РФ об административных правонарушениях // СПС «Консультант Плюс»

2. Налоговый кодекс РФ. Часть вторая // СПС «Консультант Плюс»

3. Федеральный закон от 06.12.2011 г. № 402-Ф3 «О бухгалтерском учете» // СПС «Консультант Плюс»
4. Федеральный закон от 03.07.2016 № 290Ф3 «О внесении изменений в Федеральный закон «О применении контрольно-кассовой техники при осуществлении наличных денежных расчетов и (или) расчетов с использованием платежных карт» и отдельные законодательные акты Российской Федерации» // СПС «Консультант Плюс» 
4. Федеральный закон от 22.05.2003 № 54Ф3 «О применении контрольно-кассовой техники при осуществлении наличных денежных расчетов и (или) расчетов с использованием электронных средств платежа» // СПС «Консультант Плюс»

5. Петрухина Т. Онлайн-кассы: инструкция по применению // Практическая бухгалтерия. 2016. № 9.

6. Слабинская И.А. К вопросу о сущности информации о движении денежных средств // Вестник Белгородского государственного тех- нологического университета им. В.Г. Шухова. 2014. № 4. C. 118-122.

7. Слабинская И.А., Слабинский Д.В. Денежные средства, их функции и виды расчетных операций, как объект бухгалтерского учета // Белгородский экономический вестник. 2015. № 2 (78). С. 105-117.

8. http://www.nalog.ru

9. http://www.1gl.ru

10. http://www.consultant.ru

11. http://www.gazeta-unp.ru/onlayn-kkt

\section{Bryantseva T.A., Shevchenko M.V.}

\section{THE FEATURES OF ONLINE-CASHBOX}

The article discusses the features of the organization of the settlement system with the use of on-line cashboxs, imposed in connection with a change in federal law in 2017 and designed to simplify the implementation of tax control over the use of cash registers trade organizations, including in the construction industry. Key words: cash transactions, check-out equipment, online ticket office, the operator of fiscal data, the fiscal drive

Брянцева Татьяна Алексеевна, кандидат экономических наук, старший преподаватель. Белгородский государственный технологический университет им. В.Г. Шухова.

Адрес: Россия, 308012, г. Белгород, ул. Костюкова, 46.

E-mail tatyana.shapoval@mail.ru

Шевченко Мария Владимировна, старший преподаватель.

Белгородский государственный технологический университет им. В.Г. Шухова.

Адрес: Россия, 308012, г. Белгород, ул. Костюкова, 46.

E-mail shevmv@mail.ru 